Scientists in journalism

\title{
A day in the working life of Christine McGourty,
}

\section{science and technology correspondent for BBC television and radio}

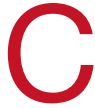
hristine McGourty's day begins just before 7 am when she switches on the Today programme to listen to the radio news. As she prepares herself for work and her children for the day, she keeps one eye on breakfast television.

On this particular day McGourty was keen to hear how her report prepared the day earlier sounded on air. The story was about signals from rats' brains powering a robot arm and was based on a scientific paper published in Nature Neuroscience. All of the top journals, including Science and Cell, provide material for radio and television news stories, along with electronic sources of science news such as AlphaGalileo, BioMedNet and Eureka.

All was well with the rat story. No inadvertent mistakes had been introduced during the editing. By 8 am, McGourty was talking to the television producer for the BBC's news at one, who wanted to know if the radio story could be redone for television. McGourty's answer was yes, but that left only two hours to get suitable footage and find another interviewee who could say more than had already been reported on the Today programme.

Frustratingly, the US researchers had footage but were reluctant to release it because of potential reprisals from animal rights activists. Shelving the problem for 20 minutes, McGourty did live interviews on the rat story with regional $\mathrm{BBC}$ radio stations. Then shelined up an interviewee on

he skill of the
television and radio
journalist lies in spotting
a story and rapidly
understanding and
distilling complicated
science into perhaps no
more than 250 words

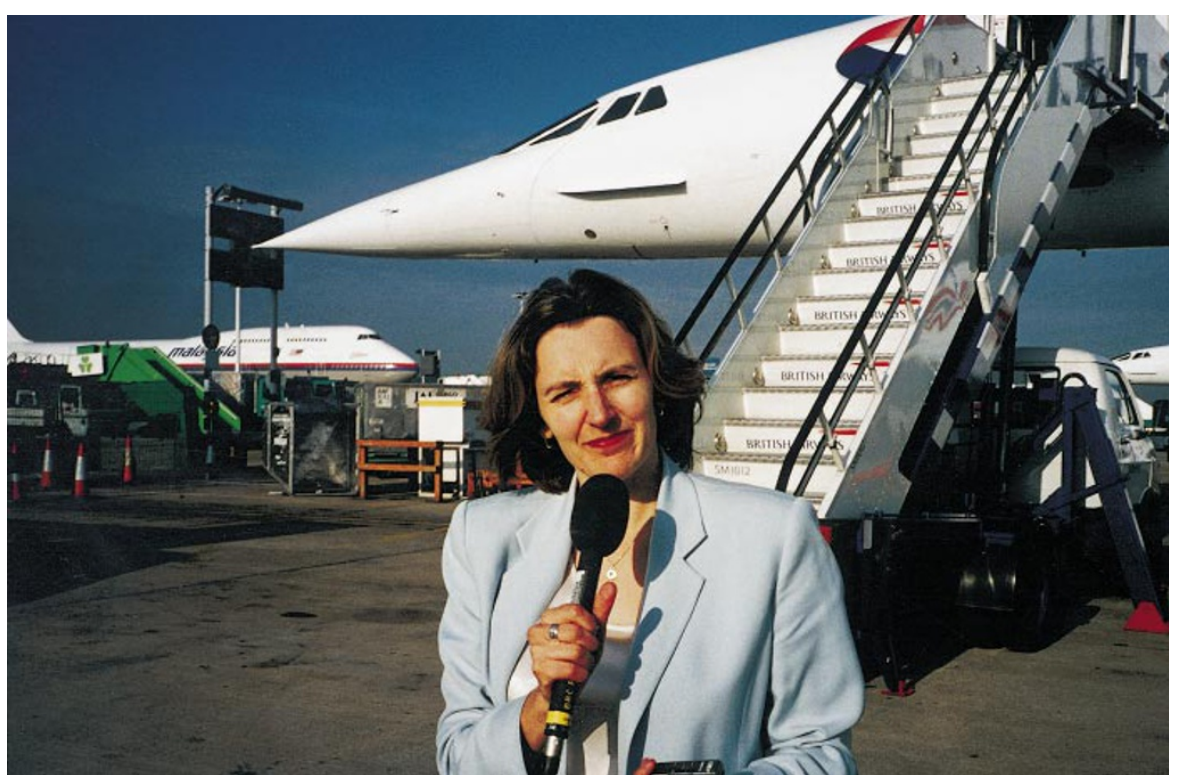

High flyer: McGourty prepares to chase August's solar eclipse.

the rat story for the news at one, and by 9.30 am was driving across London to the BBC Television Centre at White City. En route, the producer telephoned and cancelled the piece. McGourty diverted to catch a train to Bletchley to film interviews about the future of the historic Second World War code breaker's site.

While McGourty headed for Bletchley with a film crew to talk with the chief executive and record the clatter of the enigma machines, a producer was on her way to Sheffield to interview one of the code breakers. Both headed back to London in the early evening and from $7 \mathrm{pm}$ onwards McGourty viewed the footage, chose clips and wrote and recorded her television script. All this was left for overnight editing. In the meantime, McGourty recorded a radio track for the early morning news and left for home at $10 \mathrm{pm}$. The next morning, the routine began again with a producer from the news at one discussing how they could use the Bletchley story that lunch time.

The skill of the television and radio journalist lies in spotting a story and rapidly understanding and distilling complicated science into perhaps no more than 250 words. The task can be particularly difficult

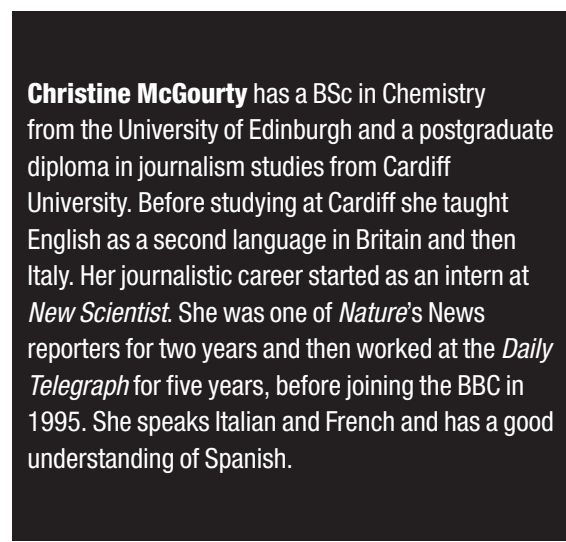

for a daytime audience that is unlikely to have many science qualifications. To aid understanding and make the story lively, graphics can be commissioned and interesting interviewees need to be found.

On intense days, such as when McGourty worked on the rat and Bletchley stories, the deadlines are relentless and must be met throughout the day. Typically, the BBC's specialist correspondents work long, intense hours perhaps twice a week. On other days, the correspondents reach home earlier. "The job can be nerve wracking," says McGourty, with commendable understatement. 